\title{
Publisher Correction: The expanding landscape of inflammatory cells affecting cancer therapy
}

Ralph Weissleder (iD and Mikael J. Pittet (D)

Correction to: Nature Biomedical Engineering https://doi.org/10.1038/s41551-020-0524-y, published 18 March 2020.

In the version of the Perspective originally published, in Fig. $1 \mathrm{c}$ the data for $\mathrm{DC}_{2}$ were mistakenly duplicated from the data for $\mathrm{DC}_{1}$, and the data for $\mathrm{DC}_{3}, \mathrm{pDC}, \mathrm{Mono}_{1-4}$ and $\mathrm{Mø} \varnothing_{1-\mathrm{cycl}}$ were incorrectly plotted. These errors have now been corrected, and the original and corrected panels are shown below.
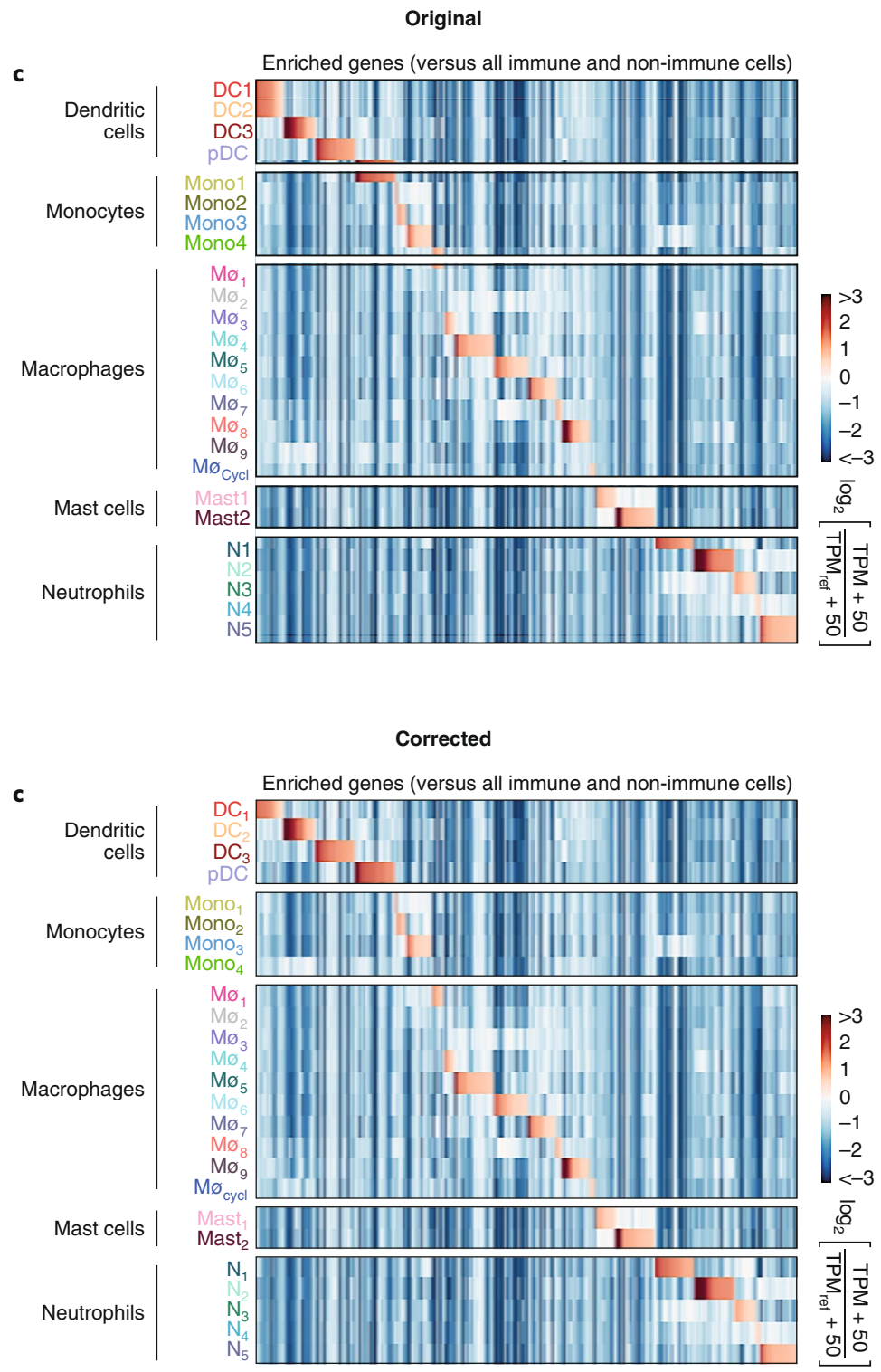

Fig. 1 | Original and Corrected.

Published online: 6 April 2020

https://doi.org/10.1038/s41551-020-0554-5

๑) Springer Nature Limited 2020 